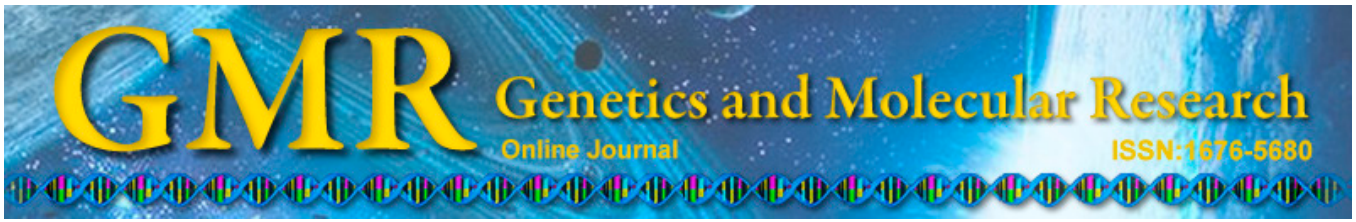

\title{
Treating congenital megacolon by \\ transplanting GDNF and GFR $\alpha-1$ double genetically modified rat bone marrow mesenchymal stem cells
}

\author{
C.B. Zhou, C.H. Peng, W.B. Pang, D. Zhang and Y.J. Chen \\ Third Department of Surgery, Beijing Children's Hospital, Beijing, China \\ Corresponding author: Y.J. Chen \\ E-mail: chenyajuntds@yeah.net
}

Genet. Mol. Res. 14 (3): 9441-9451 (2015)

Received November 3, 2014

Accepted March 26, 2015

Published August 14, 2015

DOI http://dx.doi.org/10.4238/2015.August.14.8

\begin{abstract}
We studied the survival and gene expression of glial cell line-derived neurotrophic factor (GDNF) and GDNF receptor $\alpha-1$ (GFR $\alpha-1)$ double-genetically modified rat bone marrow mesenchymal stem cells (BMSCs) transplanted into the intestinal walls of the rat models with congenital megacolon and determine the feasibility of treatment by transplantation of double-genetically modified rat BMSCs. The rat colorectal intestinal wall nerve plexus was treated with the cationic surface active agent benzalkonium chloride to establish an experimental megacolon model. The rat target genes GDNF and GFR $\alpha-1$ were extracted and ligated into pEGFP-N1. Eukaryotic fluorescent expression vectors carrying the GDNF and GFR $\alpha-1$ genes were transfected into BMSCs by in vitro culture. We treated congenital megacolon by transplanting double-genetically modified rat bone marrow mesenchymal stem cells. The pEGFP-EGFP-GDNF-GFR $\alpha-1$ double-gene co-expressing the eukaryotic expression plasmid vector was successfully established. Protein gene protein 9.5 and vasoactive intestinal peptide-positive ganglion cells showed no positive expression
\end{abstract}


in the phosphate-buffered saline transplantation group based on an immunofluorescence test at 1,2 , and 4 weeks after transplantation of BMSCs. Additionally, compared with the phosphate-buffered saline transplantation group, the expression of rearranged during transfection, GDNF, and GFR $\alpha-1$ mRNA in the stem cell transplantation group increased gradually. The double-genetically modified BMSCs colonized and survived in the intestinal wall of the experimental megacolon rat model and expressed related genes, partially recovering the colonic neuromuscular regulatory functions and thus providing an experimental basis for treating congenital megacolon by cellular transplantation.

Key words: Bone marrow mesenchymal stem cells; Transplantation; Congenital megacolon; Glial cell-derived neurotrophic factor

\section{INTRODUCTION}

Congenital megacolon (Hirschsprung's disease) is a common intestinal nervous system developmental dysfunctional disease that is also known as aganglionosis. The morbidity of HD is approximately 1:5000 (Kenny et al., 2010) and more common among male pediatric patients. Currently, congenital megacolon is treated primarily by surgery, which involves excision of the intestinal canal with ganglions. However, post-operative constipation relapse and complications such as fecal incontinence and anal stenosis will severely affect pediatric patients' physiology and psychology (Kim and Oh, 2009; Tannuri et al., 2009). Particularly, there are no ideal therapeutic measures for long-segment type and full-colon type megacolon. In recent years, studies of the culture, induced differentiation, and transplantation of bone marrow mesenchymal stem cells (BMSCs) (Friedenstein et al., 1968) has brought new hope for treating congenital megacolon by cellular transplantation and has become a research hotspot.

BMSCs are adult stem cells originating in the mesenchyma (Delorme et al., 2006) and show multi-directional differentiation potential and plasticity. In addition, easy in vitro separation and culture, massive expansion, low immunological rejection, self-renewal, and autologous replantation of BMSCs (Ippolitog et al., 2004) enable these cells to have important clinical application value and prospects in gene therapy and cell replacement therapy and have become an ideal seed cell source in histological engineering. Studies of the application of BMSCs have made it possible to transplant, repair, and reconstruct the enteric nervous system and recover the intestinal functions for radical treatment of congenital megacolon.

In the study, the BMSCs of adult rats were separated, cultured, and expanded in vitro (Metzger, 2010; Wang et al., 2010). BMSCs were modified using the exogenous glial cellderived neurotrophic factor (GDNF) and glial cell-derived neurotrophic factors receptor 1- $\alpha$ $(\mathrm{GFR} \alpha-1)$ co-transfection gene. BMSCs were subjected to intestinal neural induction and differentiation in vitro and the cells were transplanted into the diseased intestinal canal of the benzalkonium chloride (BAC) experimental rat megacolon model after induced differentiation (Sato et al., 1978; Mortell et al., 2006; Vespúcio et al., 2008). We found that the cells could survive, settle, and proliferate locally, partially recover the intestinal functions, and improve intestinal functions. A preliminary study was conducted for treating congenital megacolon by transplanting BMSCs. 


\section{MATERIAL AND METHODS}

\section{Experimental specimens}

The rats used in the experiment for separation and culture of BMSCs were clean male Sprague-Dawley (SD) rats weighing $100 \mathrm{~g}$ (Nanjing Better Biotechnology Co., Ltd., Nanjing, China); the rats used to establish and identify SD rat experimental megacolon models included 110 clean SD rats (male or female) aged 8 weeks and weighing $200 \pm 15 \mathrm{~g}$. The rats used to establish the GDNF and GFR $\alpha-1$ double-gene eukaryotic expression vector included 4 clean SD immature male or female rats that were less than 7 days old. The rat used for the experiment of the pEGFP-EGFP-GDNF-GFR $\alpha$-1 eukaryotic expression vector was 1 clean male SD rat aged 1 month and weighing approximately $100 \mathrm{~g}$.

\section{Separation and culture of rat BMSCs}

In the experiment, BMSCs were separated and cultured using the pure adherence method (Ringdén et al., 2006) and their biological characteristics were preliminarily identified. The rats were placed in $40^{\circ} \mathrm{C}$ phosphate-buffered saline containing double-antibody to further separate the soft tissue on the marrow cavity. The marrow cavity was washed with the L-DMEM complete culture solution. The bone marrow cell suspension was collected, inoculated into a culture flask, and cultured in an incubator at $5 \% \mathrm{CO}_{2}$ at $37^{\circ} \mathrm{C}$. The solution was replaced (half volume) at $48 \mathrm{~h}$ and then replaced every 3 days or when the culture medium became yellow. Non-adherent cells were removed and digested with $0.25 \%$ pancreatin for passaging when the cells grew to $90 \%$ fusion. Cell morphology was observed under an inverted microscope each day.

\section{Establishment and identification of SD rat experimental megacolon models}

The rat colorectal wall nerve plexuses were treated with the cationic surface active agent BAC to establish an experimental megacolon model. The clean SD rats aged 8 weeks were randomly divided into 2 groups: model group $(\mathrm{N}=55)$, with the colon treated with 5 $\mathrm{mL} / \mathrm{LBAC}$, and control group $(\mathrm{N}=55)$ with the colon treated with normal saline.

\section{Establishment of GDNF and GFRa-1 double-gene eukaryotic expression vector}

The target genes GDNF and GFR $\alpha-1$ were extracted for ligation into the pEGFP-N1 vector (Wuhan Transduction Bio Co., Ltd., Wuhan, China). They were ligated into the eukaryotic expression plasmid vector for expression of the double genes of GDNF and GFR $\alpha-1$ to explore and optimize the conditions for induced differentiation of BMSCs towards nerve cells.

\section{pEGFP-EGFP-GDNF-GFR $\alpha$-1 eukaryotic expression vector experiment}

Rat BMSCs cultured in vitro were transfected with the eukaryotic fluorescent expression vector carrying the GDNF and GFR $\alpha-1$ genes (Nanjing Genscript Biological Science and Technology Co., Ltd., Nanjing, China). We then observed the expression of GDNF and GFR $\alpha-1$ in BMSCs and their effect on induced differentiation of BMSCs towards neuron-like 
cells. At 3 and 7 days after transfection and induction, neuron-like cells and control group cells were collected. Total protein was extracted and the expression of the GDNF and GFR $\alpha-1$ proteins in the cells was determined by western blotting. Protein concentration was determined using the Bradford method. The reagent is shown in Table 1.

Table 1. Assay reagents for protein concentration.
\begin{tabular}{lrrrrrrrr}
\hline Well number & A & B & C & D & E & F & G & H \\
\hline Bovine serum albumin sample $(\mu \mathrm{L})$ & 0 & 1 & 2 & 3 & 4 & 6 & 8 & 10 \\
PBS $(\mu \mathrm{L})$ & 50 & 49 & 48 & 47 & 46 & 44 & 42 & 40 \\
Coomassie brilliant blue $(\mu \mathrm{L})$ & 50 & 50 & 50 & 50 & 50 & 50 & 50 & 50 \\
Corresponding amount of protein $(\mu \mathrm{g})$ & 0 & 1 & 2 & 3 & 4 & 6 & 8 & 10 \\
\hline
\end{tabular}

\section{Primary study on treating congenital megacolon by transplanting double-genetically modified rat BMSCs}

Three weeks after establishing the megacolon model (Martucciello et al., 1995; Newgreen and Young, 2002), the surviving model rats were intraperitoneally injected with $0.03 \%$ pentobarbital sodium for anesthesia. A median incision was made aseptically. The cell suspension was slowly injected into the diseased intestinal wall using a microsyringe at 5-6 sites. The rats in both groups were observed for changes in mental state, abdominal distension, and defecation each day after operation. Two rats were selected from each group at $1,2,4$, and 8 weeks after transplantation and observed for changes of the intestinal canal on the transplanted section. Two rats were randomly selected from each group at 2 weeks after operation. The colon of the treated section was subjected to routine hematoxylin and eosin staining and acetylcholinesterase immunohistochemical and immunofluorescence tests for the expression of protein gene protein (PGP9.5) and vasoactive intestinal peptide proteins. Three rats were selected from each group at 1, 2, 4, and 8 weeks after transplantation. The intestinal canal of the transplanted section was washed with phosphate-buffered saline and stored in a refrigerator or liquid nitrogen at $-80^{\circ} \mathrm{C}$, and subjected to real-time polymerase chain reaction (PCR) testing for expression of GDNF, GFR $\alpha-1$, and rearranged during transcription (RET) mRNA.

The RET primer sequences were as follows: upstream primer: 5'-CTCAAGTGATGC TTACTGG-3'; RET downstream primer: 5'-ACTTGGGAAGGTGTCCTT-3'. The following reactions conditions were used: $50^{\circ} \mathrm{C}$ for $2 \mathrm{~min}, 95^{\circ} \mathrm{C}$ for $2 \mathrm{~min}$ for pre-denaturation; $94^{\circ} \mathrm{C}$ for $15 \mathrm{~s}, 58^{\circ} \mathrm{C}$ for $15 \mathrm{~s}$, and $72^{\circ} \mathrm{C}$ for and $45 \mathrm{~s}$ for a total of 40 cycles; extension at $72^{\circ} \mathrm{C}$ for 10 min. The GDNF primer sequences were as follows: upstream primer: 5'-TGGGATGTCGTG GCTGTCTG-3'; downstream primer: 5'-GCCGCTTGTTTATCTGGTGAC-3'. The following reaction conditions were used: $50^{\circ} \mathrm{C}$ for $2 \mathrm{~min}, 95^{\circ} \mathrm{C}$ for $2 \mathrm{~min}$ for pre-denaturation; $94^{\circ} \mathrm{C}$ for $15 \mathrm{~s}, 58^{\circ} \mathrm{C}$ for $15 \mathrm{~s}$, and $72^{\circ} \mathrm{C}$ for $45 \mathrm{~s}$ for a total of 40 cycles; extension at $72^{\circ} \mathrm{C}$ for $10 \mathrm{~min}$. The GFR- $\alpha-1$ primer sequences were as follows: upstream primer: 5'-CCTCAGCCATTGAC ATTCGG-3'; downstream primer: 5'-CCTGGCTTCTTTACACCTCGTT-3'. The following reaction conditions were used: $50^{\circ} \mathrm{C}$ for $2 \mathrm{~min}, 95^{\circ} \mathrm{C}$ for $2 \mathrm{~min}$ pre-denaturation; $94^{\circ} \mathrm{C}$ for 15 $\mathrm{s}, 58^{\circ} \mathrm{C}$ for $15 \mathrm{~s}$, and $72^{\circ} \mathrm{C}$ for $45 \mathrm{~s}$ for a total of 40 cycles; extension at $72^{\circ} \mathrm{C}$ for $10 \mathrm{~min}$. The actin primer sequences were as follows: upstream primer: 5'-CGTTGACATCCGTAAAGAC CTC-3'; downstream primer: 5'-TAGGAGCCAGGGCAGTAATCT-3'. The following reaction conditions were used: $50^{\circ} \mathrm{C}$ for $2 \mathrm{~min}, 95^{\circ} \mathrm{C}$ for 2 min pre-denaturation; $94^{\circ} \mathrm{C}$ for $15 \mathrm{~s}$, $58^{\circ} \mathrm{C}$ for $15 \mathrm{~s}$, and $72^{\circ} \mathrm{C}$ for $45 \mathrm{~s}$ for a total of 40 cycles; extension at $72^{\circ} \mathrm{C}$ for $10 \mathrm{~min}$. 


\section{RESULTS}

\section{Separation and culture of rat BMSCs}

Based on the separation and culture of rat BMSCs, there were numerous blood cells after primary culture using the complete bone marrow adherent cell culture method, which affected the adherence of BMSCs. A small number of adherent cells grew and most cells were suspended at $24 \mathrm{~h}$ after inoculation. A large number of suspended blood cells were removed after the solution was replaced at $48 \mathrm{~h}$, thus contributing to adherence and growth of additional BMSCs. The cells were circular and spindle-shaped (Figure 1A). The cells number increased gradually after being cultured for 5 days and were shuttle-shaped or polygonal. Partial cells grew in a nesting form (Figure 1B). Cellular proliferation became active at 7-8 days. Several fibroblast-like colonies were observed, arranged in a spiral or radial form (Figure 1C). Cellular fusion reached over 90\% after 12-14 days. Uniform long spindle-shaped cells were formed after repeated solution replacement and digestion and passaging to the 3rd passage. The cells were characterized as having a clear boundary, strong refractivity, and plump nucleus (Figure 1D). The immunocytochemical method was used to test the marker antigens of CD44 and CD90 on bone marrow stroma stem cells and the marker antigen CD45 on hematopoietic stem cells. Based on the results of the immunocytochemical test, the mesenchymal stem cell markers CD44 (91.7\%) and CD90 (89.6\%) were highly expressed in the cultured BMSCs (Figure 1E). The cells exhibited positive expression and the cytoplasm was stained with claybank. The hematopoietic cell marker CD45 was not expressed (Figure 1F). The cells exhibited negative expression and the cytoplasm was not stained (Figure 1G), indicating that the cultured cells were BMSCs.
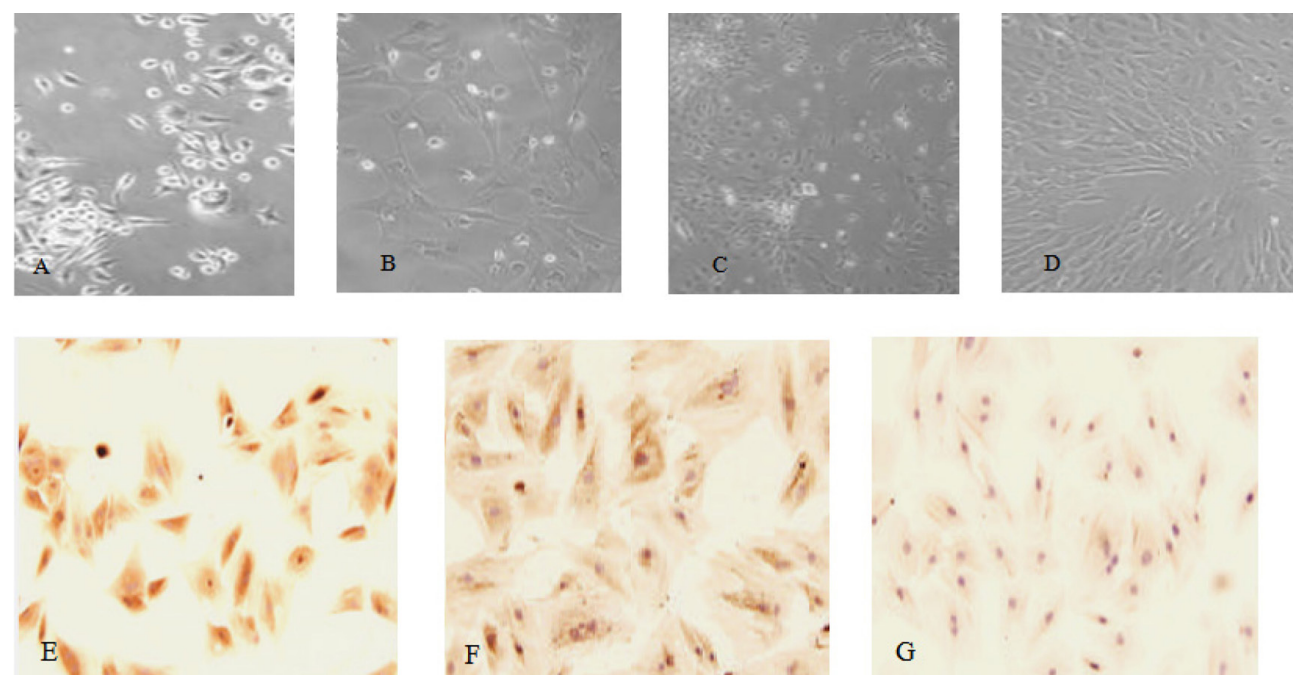

Figure 1. Micrograph for culture of whole bone marrow adherent cells. A. For cells cultured for 48 h, partial cells grew on the surface. The cells were circular and spindle-shaped. B. The cells increased after culture for 5 days and the cells were shuttle-shaped or polygonal. C. The cells formed a typical colony-like cell growth morphology after culture for 7 days. D. The cells grew rapidly and were arranged in order and fused mutually (X10) after culture for 10 days; Immunohistochemical testing of cell culture: $\mathbf{E}$. and $\mathbf{F}$. were expression of the CD44 and CD90 cells cultured. The cells exhibited positive expression and the cytoplasm was stained with claybank. G. Test of CD45 cell culture. The cells exhibited negative expression and the cytoplasm was not stained (20X). 


\section{Establishment and identification of SD rat experimental megacolon models}

The rats in the model group suffered from abdominal distension and decreased feeding and defecation at 1 week after operation. The rats suffered from severe abdominal distension, non-defecation or a small amount of dry and hard excrement, and cachexia. Spasm and stenosis occurred in the BAC treated segment of the colon after gross anatomy. The stenosis segment was $2-3 \mathrm{~cm}$ in length on average. The proximal intestinal canal was dilated and content accumulated within the enteric cavity (Figure 2A).

Ganglion cells of the myenteric nerve plexus of the colonic wall of the treated segment were absent, nerve fibers had proliferated, the intestinal wall were thickened and hardened, there was no significant damage to the mucous epithelium and muscular layer, and there were no scars formed in the model group 4 weeks after operation based on hematoxylin and eosin staining (Figure 2B). The acetylcholinesterase immunohistochemical test results indicated that no positive submucosal and intermuscular ganglion cells were present and that intermuscular ganglion cells disappeared based on the neurone-specific enolase and PGP9.5 immunofluorescence staining for the model group (Figure $2 \mathrm{C}$ and $\mathrm{D}$ ). The acetylcholinesterase histochemical staining indicated there was no significant positive nerve fiber proliferation at 2 weeks; there were claybank-stained proliferated nerve fibers; the fibers were thickened and distorted compared with the control group at 4 weeks (Figure 2E).
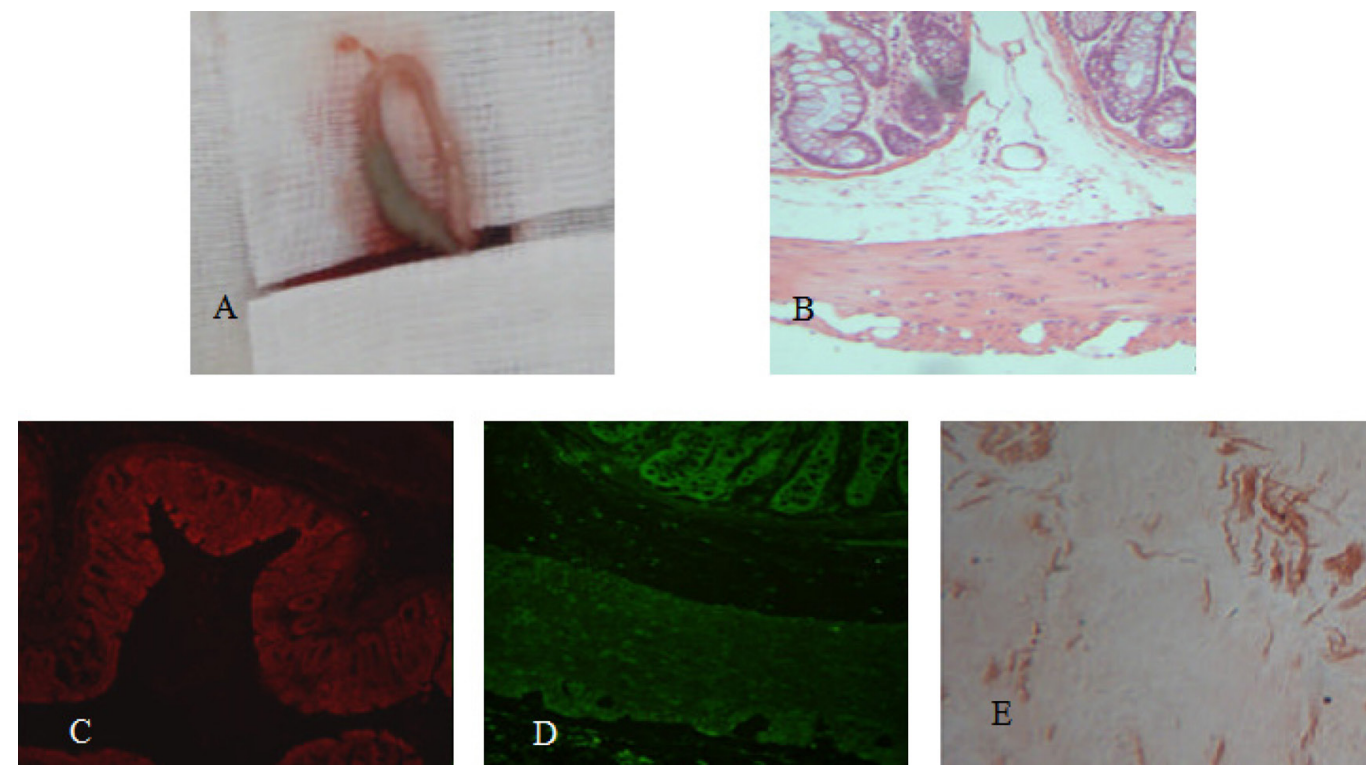

Figure 2. Pathological and immunohistochemical of megacolon models. A. We observed stenosis of the intestinal canal of the treated section, dilatation of the proximal intestinal canal, a large amount of intestinal content retained $(10 X)$ at 4 weeks after modeling; B. Hematoxylin and eosin staining results: The intermuscular ganglion cells of the intestinal canal in the model group disappeared (20X); C. For the immunofluorescence test for NSE, the intermuscular ganglion cells disappeared (20X); D. For the immunofluorescence test for PGP9.5, the intermuscular ganglion cells disappeared (20X); E. For the acetylcholinesterase histochemical staining observation, the cholinergic nerve fibers proliferated and were distorted (20X). 


\section{Establishment of GDNF and GFR $\alpha-1$ double-gene eukaryotic expression vector}

Total RNA was extracted from the brain tissue of the newly-born rats and amplified by reverse transcription-PCR to obtain the GDNF and GFR $\alpha-1$ target gene segments. The recombinant plasmids pEGFP-GDNF and pEGFP-GFR $\alpha-1$ were amplified to obtain bands with a size equal to the expected target gene after transformation and culture (Figure 3A). The recombinant plasmids of pEGFP-GDNF-GFR $\alpha-1$ could be amplified by PCR to obtain bands with a size equal to the expected target gene after transformation and culture (Figure $3 \mathrm{~B})$. Gene sequencing results coincided with the sequences of the 2 target genes in GenBank. Based on the double enzyme digestion, the target genes were equal to the 2 cDNA bands of the plasmid in size, indicating that the pEGFP-GDNF-GFR $\alpha-1$ recombinant eukaryotic expression plasmid was successfully established.
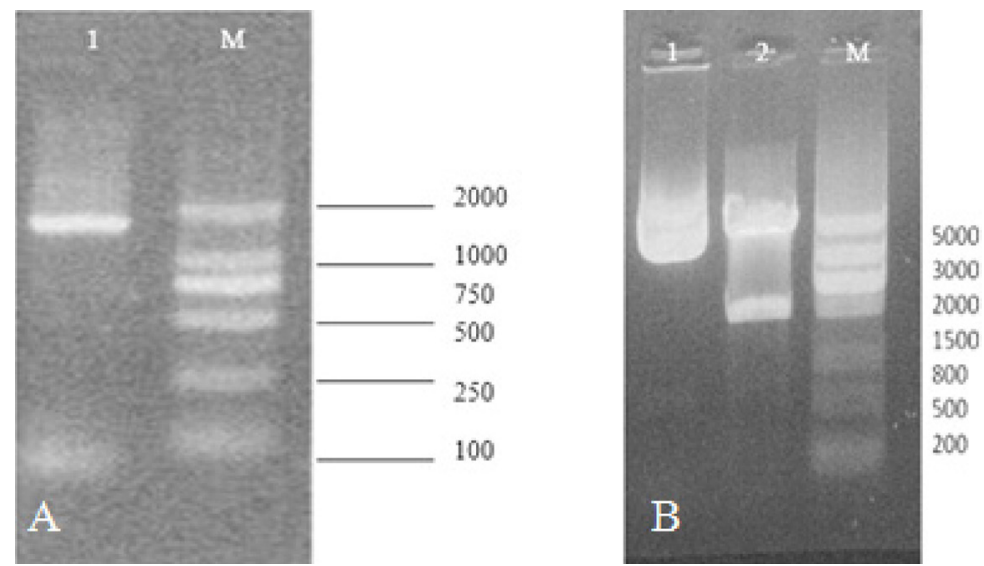

Figure 3. A. Electrophoretogram for gene products from amplification of GDNF/GFR $\alpha-1$ : Lane $M$-marker, 1-DNA; B. electrophoretogram for recombinant plasmid pEGFP-GDNF-GFR $\alpha-1$ double enzyme digestion result: Lane $M$-marker, lane 1-plasmid, lane 2-double enzyme digestion result.

\section{pEGFP-EGFP-GDNF-GFR $\alpha$-1 eukaryotic expression vector experiment}

In terms of the expression of the pEGFP-EGFP-GDNF-GFR $\alpha-1$ eukaryotic expression vector in the rat BMSCs and the neural induction results, the neuron markers neuronespecific enolase and neurofilaments were positively expressed in the experimental group after induced differentiation based on the immunofluorescence test. Neurone-specific enolase exhibited green fluorescence (Figure 4A). NF exhibited red fluorescence (Figure 4B). The glial cell marker glial fibrillary acidic protein was negative. Total protein was extracted from the cells after induction for 3 and 7 days. Based on western blotting results, expression of GDNF and GFR $\alpha-1$ increased at 7 days after induction (Figure 4C).

\section{Primary study on treating experimental congenital megacolon by transplanting double-genetically modified rat BMSCs}

Based on observation, rats in the experimental and control groups suffered from abdominal distension, dry and hard defecation, and constipation after transplantation. Some rats 
even suffered from cachexia and non-defecation. The symptoms of rats in the experimental group were less severe than those in the control group. Based on the anatomy at 4 weeks after transplantation, there were strictures of different degrees in both groups. Dry and hard coprolith and intestinal canal dilation were present within the upper intestinal canal of the stricture in the control group, while defecation was formed and wet and no significant dry and hard coprolith was present in the upper intestinal canal of the stricture after transplantation.
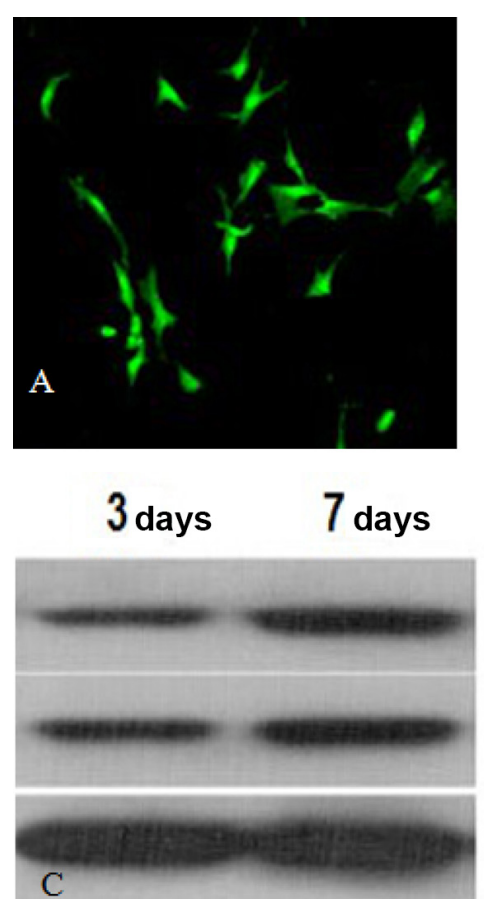

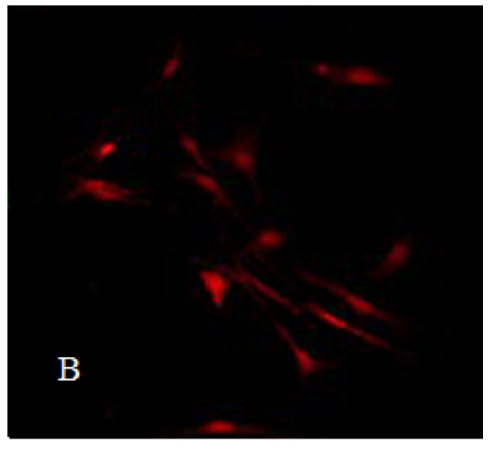

GDNF

\section{GFR $0-1$}

\section{GAPDF}

Figure 4. Situation of the plasmid expressing. A. and B. Cellular immunity fluorescence detection after induced differentiation. NSE (A) was green fluorescence and NF (B) was red fluorescence (20X); C. expression of GDNF and GFR $\alpha-1$ was present in the cells 3 and 7 days after western blot detection and induction. The expression increased gradually.

The pathological and histological results indicated that the ganglion cells in the myenteric nerve plexus in the colonic wall of the treated segment were absent and nerve fibers proliferated in the control group based on the hematoxylin and eosin staining and histochemical detection. There were transplanted neuron-like cells and no significant nerve fiber proliferation in the experimental group. No significant mucous epithelium and muscular layer damage were present in either group.

Positive expression of PGP9.5 red fluorescence (Figure 5A) and vasoactive intestinal peptide green fluorescence (Figure 5B) was observed in cells in the muscular layer of the intestinal canal based on immunofluorescence detection at 1 week after transplantation, while there was no positive expression in the control group. There were extensive and increased cells with positive expression of fluorescence at 4 weeks after transplantation, indicating that the transplanted cells colonized, survived, divided, proliferated, and migrated. The relative expression levels of GDNF, GFR $\alpha-1$, and RET mRNA in the intestinal canal of the transplanted 
segment in the experimental group increased gradually, demonstrating that the transplanted cells colonized, survived, and proliferated continuously in the local intestinal canal (Figure 5C).

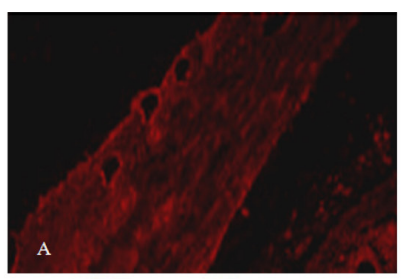

3 days

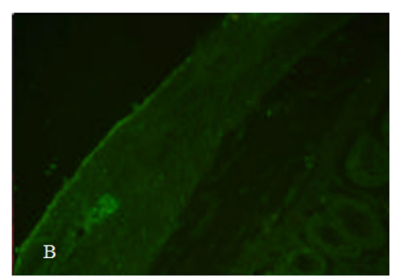

7 days

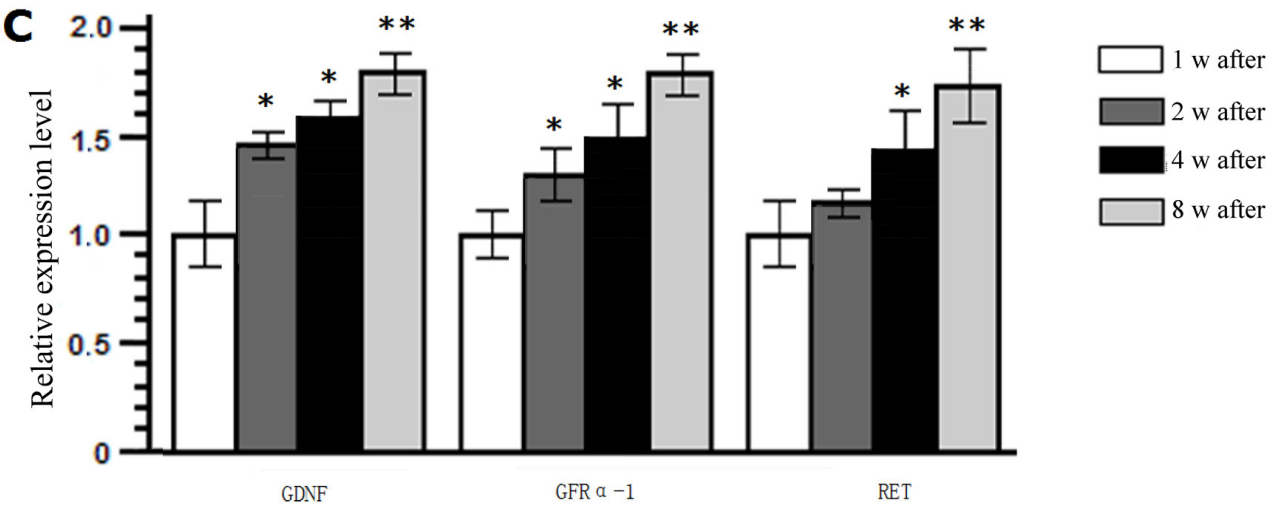

Figure 5. Immunofluorescence detection of PGP9.5 and VIP expression after transplantation. A. PGP9.5, there were ganglion cells with red positive fluorescence. B. VIP, there were ganglion cells with green positive fluorescence. C. real-time PCR detection of the changes in expression of GDNF, GFR $\alpha-1$, and RET mRNA at $1,2,4$, and 8 weeks after transplantation. The relative expression levels of GDNF, GFR $\alpha-1$, and RET mRNA increased gradually.

\section{DISCUSSION}

BMSCs exhibit numerous biological advantages including self-renewal, multi-directional differentiation potential, stable genetic background, and low immunogenicity, among others, and can be used as a gene vector (Hamada et al., 2005; Schrepfer et al., 2007; Sasaki et al., 2009; Trzaska et al., 2009) for in vivo transplantation therapy.

In this study, BMSCs separated and purified in vitro using the pure adherence method showed characteristics of stem cells, including high purity, fast proliferation, and stable growth traits. This method is simple to operate, practical, and is inexpensive. The megacolon rat models were similar human megacolon in terms of histopathological examination and clinical symptoms and were easily operated. In this study, the neurotrophic factors GDNF and GFR $\alpha-1$ that played an important nutrition and regulatory role in differentiation of intestinal nerve cells and fetal gut culture medium were used to induce differentiation of intestinal nerve cells in vitro for transformation into BMSCs. After induced and differentiated intestinal neuron-like cells were transplanted into the diseased intestinal wall of the rat models without ganglion cells, there was no improvement in the symptoms of the rats in the control group after operation, including abdominal distension and constipation, and the symptoms were 
gradually exacerbated. Symptoms improved at 2 weeks after operation in the transplantation group. Neuronal cells showed positive expression of PGP9.5 and vasoactive intestinal peptide, indicating that the transplanted nerve cells were colonized successfully and proliferated continuously.

Based on the reverse transcription-PCR detection, the expression of GDNF and GFR $\alpha-1$ mRNA in the transplanted intestinal wall and the expression of RET mRNA was observed. Thus, the transplanted intestinal nerve cells colonized and proliferated on the intestinal wall and secreted the RET protein after stimulation by local environmental factors, activating the RET/GDNF signal pathway and further promoting division of the intestinal neuron-like cells (Natarajan et al., 2002; Metzger, 2010; Wang et al., 2010). The intestinal neuron-like cells transfected in the experiment carried the green fluorescent protein gene, which was transcribed, translated, and expressed along with the cellular genomes, thus allowing for dynamic observation of changes in the transplanted cells, such as distribution and migration (Makino et al., 1999; Brazelton et al., 2000). Care should be taken to control the depth and direction of needle insertion during local injection for cellular transplantation as the colonic wall is very thin. An excessive insertion depth enables the needle to enter the enteric cavity, thus leading to invalid transplantation. An insufficient insertion depth enables the needle to only enter the seromuscular layer, thus causing susceptibility to exosmosis of the cell suspension and affecting the transplantation results. Thus, a microsyringe was used for inclined insertion, which allowed us to control the depth of insertion into the intestinal wall. Injection was performed slowly and retained for 3-5 min, enabling the cell suspension to sufficiently scatter and avoiding leakage of the cell suspension. In the study, rat BMSCs were separated, cultured, and purified in vitro. The intestinal neuron-like cells were induced and differentiated at the gene level. The induced and differentiated cells carrying the green fluorescent protein gene were transplanted into the intestinal wall of the megacolon rat model. The transplanted intestinal neuron-like cells colonized, differentiated, and proliferated on the intestinal wall. These cells repaired and reconstructed the myenteric nerve plexus of the diseased intestinal section and improved intestinal functions, thus providing a new potential method for treating intestinal motility neurological disorder diseases such as congenital megacolon by transplantation of mesenchymal stem cells. Further studies are required to determine the timing of BMSC transplantation, transplantation approach, cell concentration, long-term effect following transplantation, and homing to corresponding tissues.

\section{REFERENCES}

Brazelton R, Rossi V, Keshet I and Blau HM (2000). From marrow to brain: expression of neuronal phenotypes in adult mice. Science 290: 1775-1779.

Delorme B, Chateauvieux S and Charbord P (2006). The concept of mesenchymal stem cells. Regen Med. 1: 497-509.

Friedenstein AJ, Petrakova KV, Kurolesova AJ, Ivanovna A, et al. (1968). Heteroopic transplants of bone marrow: analysis of precursor cells for osteogenic and hematopoietic tissues. Transplantation 6: 230-247.

Hamada H, Kobune M, Nakamura K, Kawano Y, et al. (2005). Mesenchymal stem cells (MSC) as therapeutic cytoreagents for gene therapy. Cancer Sci. 96: 149-156.

Ippolitog D, Diabira S, Howard GA, Menei P, et al. (2004). Marrow-isolated adult multilineage inducible (M I AM I) cells, a unique population of postnatal young and old human cells with extensive expansion and differentiation potential. J. Cell Sci. 117: 2971-2981.

Kenny SE, Tam PK and Garcia-Barcelo M (2010). Hirschsprung's disease. Semin. Pediatr. Surg. 19: 194-200.

Kim HY and Oh JT (2009). Stabilization period after 1-stage transanal endorectal pull-through operation for Hirschsprung disease. J. Pediatr. Surg. 44: 1799-1804. 
Makino S, Fukuda K, Miyoshi S, Konishi F, et al. (1999). Cardiomyocytes can be generated from marrow stromal cells in vitro. J. Clin. Invest. 103: 697-705.

Martucciello G, Faver A, Takahashi M and Jasonni V (1995). Immunohistochemical localization of RET protein in Hirschsprung's disease. J. Pediatr. Surg. 30: 433-436.

Metzger M (2010). Neurogenesis in the enteric nervous system. Arch. Ital. Biol. 148: 73-83.

Mortell A, Montedonico S and Puri P (2006). Animal models in pediatric surgery. Pediatr. Surg. Int. 22: 111-128.

Natarajan D, Marcos-Gutierrez C, Pachnis V and de Graaf E (2002). Requirement of signalling by receptor tyrosine kinase RET for the directed migration of enteric nervous system progenitor cells during mammalian embryogenesis. Development 129: 5151-5160.

Newgreen D and Young HM (2002). Enteric nervous system: Development and developmental disturbances - part 1. Pediatr. Develop. Pathol. 5: 224-247.

Ringdén O, Uzunel M, Rasmusson I, Sundberg B, et al. (2006). Mesenchymal stem cells for treatment of therapy-resistant graft-versus-host disease. Transplantation 81: 1390-1397.

Sasaki M, Radtke C, Tan AM, Zhao P, et al. (2009). BDNF-hypersecreting human mesenchymal stem cells promote functional recovery, axonal sprouting, and protection of corticospinal neurons after spinal cord injury. J. Neurosci. 29: 14932-14941.

Sato A, Yamamoto M, Imamura K, Kashiki Y, et al. (1978). Pathophysiology of aganglionic colon and anorectum: an experimental study on aganglionosis produced by a new method in the rat. J. Pediatr. Surg. 13: 399-435.

Schrepfer S, Deuse T, Lange C, Katzenberg R, et al. (2007). Simplified protocol to isolate, purify, and culture expand mesenchymal stem cells. Stem Cells Dev. 16: 105-107.

Tannuri AC, Tannuri U and Romão RL (2009). Transanal endorectal pull-through in children with Hirschsprung's diseasetechnical refinements and comparison of results with the Duhamel procedure. J. Pediatr. Surg. 44: 767-772.

Trzaska KA, King CC, Li KY, Kuzhikandathil EV, et al. (2009). Brain-derived neurotrophic factor facilitates maturation of mesenchymal stem cell-derived dopamine progenitors to functional neurons. J. Neurochem. 110: 1058-1069.

Vespúcio MV, Turatti A, Modiano P, Oliveira EC, et al. (2008). Intrinsic denervation of the colon is associated with a decrease of some colonic preneoplastic markers in rats treated with a chemical carcinogen. Braz. J. Med. Biol. Res. 41:311-317.

Wang H, Hughes I, Planer W, Parsadanian A, et al. (2010). The timing and location of glial cell line-derived neurotrophic factor expression determine enteric nervous system structure and function. J. Neurosci. 30: 1523-1538. 